OPEN ACCESS

Edited by:

Xihui Shen,

Northwest A\&F University, China

Reviewed by:

John M. Atack

Griffith University, Australia Konstantin V. Korotkov,

University of Kentucky, United States

${ }^{*}$ Correspondence:

Catherine Duport

catherine.duport@univ-avignon.fr

Specialty section:

This article was submitted to

Infectious Diseases,

a section of the journal

Frontiers in Microbiology

Received: 12 April 2017

Accepted: 03 July 2017

Published: 26 July 2017

Citation:

Madeira J-P, Alpha-Bazin BM, Armengaud J and Duport C (2017) Methionine Residues in Exoproteins and Their Recycling by Methionine

Sulfoxide Reductase $A B$ Serve as an

Antioxidant Strategy in Bacillus cereus. Front. Microbiol. 8:1342 doi: 10.3389/fmicb.2017.01342

\section{Methionine Residues in Exoproteins and Their Recycling by Methionine Sulfoxide Reductase AB Serve as an Antioxidant Strategy in Bacillus cereus}

\author{
Jean-Paul Madeira ${ }^{1,2}$, Béatrice M. Alpha-Bazin ${ }^{2}$, Jean Armengaud ${ }^{2}$ and \\ Catherine Duport ${ }^{1 *}$
}

'Sécurité et Qualité des Produits d'Origine Végétale (SQPOV), UMR0408, Avignon Université, Institut National de la Recherche Agronomique, Avignon, France, ${ }^{2}$ Commissariat à IEnergie Atomique, Direction de la Recherche Fondamentale, Institut des Sciences du vivant Frédéric-Joliot (Joliot), Service de Pharmacologie et Immunoanalyse, Laboratoire Innovations Technologiques pour la Détection et le Diagnostic (Li2D), Bagnols-sur-Cèze, France

During aerobic respiratory growth, Bacillus cereus is exposed to continuously reactive oxidant, produced by partially reduced forms of molecular oxygen, known as reactive oxygen species (ROS). The sulfur-containing amino acid, methionine (Met), is particularly susceptible to ROS. The major oxidation products, methionine sulfoxides, can be readily repaired by methionine sulfoxide reductases, which reduce methionine sulfoxides $[\operatorname{Met}(O)]$ back to methionine. Here, we show that methionine sulfoxide reductase $A B$ (MsrAB) regulates the $\operatorname{Met}(\mathrm{O})$ content of both the cellular proteome and exoproteome of $B$. cereus in a growth phase-dependent manner. Disruption of msrAB leads to metabolism changes resulting in enhanced export of $\operatorname{Met}(\mathrm{O})$ proteins at the late exponential growth phase and enhanced degradation of exoproteins. This suggests that $B$. cereus can modulate its capacity and specificity for protein export/secretion through the growth phase-dependent expression of msrAB. Our results also show that cytoplasmic MsrAB recycles Met residues in enterotoxins, which are major virulence factors in B. cereus.

Keywords: methionine sulfoxide reductase, exoproteome, antioxidants, Bacillus cereus, metabolism

\section{INTRODUCTION}

Reactive oxygen species (ROS) are by-products of aerobic metabolism, and respiration is considered to be the major intracellular source of ROS production in bacteria (Brynildsen et al., 2013; Imlay, 2013). Methionine residues in proteins are particularly susceptible to oxidation by ROS (Vogt, 1995; Stadtman et al., 2005), resulting in methionine-S-sulfoxides [Met-S-(O)] and methionine-R-sulfoxides [Met-R-(O); (Luo and Levine, 2009; Kim et al., 2014)]. Oxidized methionine can be repaired by the antioxidant enzymes, Met-S-(O) reductase (MsrA) and Met-R-(O) reductase (MsrB). Both Msr share a common catalytic mechanism to reduce $\operatorname{Met}(\mathrm{O})$ back to Met. This catalytic mechanism leads to the formation of an intramolecular disulfide bond in the Msr and involves thioredoxin (Trx), thioredoxin 
reductase, and NADPH (Weissbach et al., 2002). It has been shown that MsrA reduces both oxidized proteins and low molecular weight $\mathrm{Met}(\mathrm{O})$-containing compounds with a similar catalytic efficiency, whereas MsrB is specialized for the reduction of $\operatorname{Met}(\mathrm{O})$ in proteins. Interestingly, both Msr types preferentially repair unfolded proteins (Tarrago et al., 2012). The genes encoding MsrA and MsrB have been identified in most living organisms. Four different types of organization have been reported for $m s r A$ and $m s r B$ : (i) $m s r A$ and $m s r B$ genes are two separate transcription units, (ii) $m s r A$ and $m s r B$ cistrons are organized as an operon, (iii) $m s r A$ and $m s r B$ cistrons form a single open reading frame (ORF) to produce a two domain protein, and (iv) $t r x, m s r A$, and $m s r B$ cistrons form a single ORF to produce a three domain protein (Drazic and Winter, 2014).

Several studies have revealed the importance of Met oxidation and Msrs, especially regarding oxidative stress resistance and metabolism under stress conditions. In addition, Msrs have also been reported to be important virulence factors in pathogens by modulating a range of properties such as adherence (Wizemann et al., 1996; Giomarelli et al., 2006), motility (Hassouni et al., 1999), biofilm formation (Beloin et al., 2004), and in vivo survival (Alamuri and Maier, 2004). However, the importance of Met oxidation and Msr in the secretion of virulence factors under normal physiological conditions is largely unknown in pathogens, and in particular in Bacillus cereus.

B. cereus is a Gram-positive, motile human pathogen that is well-equipped to survive in various environments such as those encountered in soil, food and the human gastrointestinal tract (Stenfors Arnesen et al., 2008). These bacteria can grow in the presence or absence of oxygen (Rosenfeld et al., 2005; Duport et al., 2006). In the human intestine, $B$. cereus encounters oxic conditions in zones adjacent to the mucosal surface (Marteyn et al., 2010) and anoxic conditions in the intestinal lumen (Moriarty-Craige and Jones, 2004). In the presence of oxygen, $B$. cereus grows by means of aerobic respiration and secretes a large number of proteins into the extracellular compartment. These secreted proteins, and all the released proteins found in the pathogen's surrounding environment, constitute the $B$. cereus exoproteome (Clair et al., 2010, 2013; Laouami et al., 2014). We previously reported that the B. cereus exoproteome contained protein-bound $\operatorname{Met}(\mathrm{O})$ and that the accumulation of protein-bound $\operatorname{Met}(\mathrm{O})$ decreased significantly during aerobic respiratory growth, to reach its minimal value at the stationary phase (Madeira et al., 2015). Insofar as there is no ROS source and no Msr to reduce Met(O) back to Met in the extracellular milieu, we assumed that the time dynamic of protein-bound $\mathrm{Met}(\mathrm{O})$ in the $B$. cereus exoproteome could reflect the growth phase-dependent activity of an intracellular Msr. Here, we show that $B$. cereus encodes a functional MsrAB methionine sulfoxide reductase that is responsible for the decrease of the $\mathrm{Met}(\mathrm{O})$ content of the $B$. cereus exoproteome during aerobic respiratory growth. In addition, our results provide evidence that Met residues in exoproteins, especially enterotoxins, and their recycling by MsrAB, can serve as an antioxidant system that could trap ROS and maintain redox homeostasis in cells.

\section{MATERIALS AND METHODS}

\section{Construction of a $\triangle m s r A B$ Mutant and lts Complementation}

Mutant construction was performed according to the procedure developed by Arnaud et al. (2004). The msrAB ORF was interrupted by insertion of a non-polar spectinomycin resistance expression cassette, spc (Murphy, 1985) as follows. A DNA fragment of $1,413 \mathrm{bp}$ encompassing the msrAB ORF was amplified from $B$. cereus genomic DNA by PCR with primers $5^{\prime}$-gaattcTCATGCCTTGAAAGTTACGG-3' and $5^{\prime}$-agatctTTG GCGTAACGGTAATTGGT-3', which contained EcoRI and BglII restriction sites, respectively. The amplified DNA fragment was cloned into pCRXL-TOPO (Invitrogen). The resulting pCRXLmsrAB plasmid was digested with StuI. A $1.5 \mathrm{~kb} S m a \mathrm{I}$ fragment containing spc was purified from pDIA (Laouami et al., 2011) and ligated into StuI-digested pCRXLmsrAB. The resulting plasmid, pCRXLmsrAB $\triangle \mathrm{spc}$, was digested with EcoRI plus $B g l \mathrm{II}$. The $m s r A B \Delta$ spc fragment was then subcloned into EcoRI/BglII sites of pMAD (Arnaud et al., 2004). This construct was used for B. cereus transformation (Omer et al., 2015). For complementation of the $\triangle m s r A B$ mutant with wild-type $m s r A B$ gene, the 1,413 bp EcoRI-BglII fragment was cloned into pHT304 (Arantes and Lereclus, 1991). MsrAB is under the control of its own promoter into $\mathrm{pHT} 304-m s r A B$.

\section{B. cereus Strains and Growth Conditions}

Wild-type $B$. cereus ATCC 14579 without its pBClin15 plasmid (Madeira et al., 2016a,b), its $\triangle m s r A B$ mutant and $\triangle m s r A B / \mathrm{pHT} 304 m s r A B$ complemented strains were grown in MOD medium supplemented with $30 \mathrm{mM}$ glucose as the carbon source, as previously described (Madeira et al., 2016b). The inoculum was a sample of exponential subculture harvested by centrifugation, washed and diluted in fresh medium to obtain an initial optical density at $600 \mathrm{~nm}$ of 0.02 . Three independent batch cultures (biological replicates) were carried out at $37^{\circ} \mathrm{C}$ for each strain.

\section{Analytical Procedures and Growth Parameters}

$B$. cereus growth was monitored spectrophotometrically at $600 \mathrm{~nm}$. The specific growth rate $(\mu)$ was determined using the modified Gompertz equation (Zwietering et al., 1990). Cells and filtered culture supernatants were harvested at the indicated growth stage as previously described (Madeira et al., 2015, 2016b). Exoproteins were immediately precipitated from the culture supernatant using trichloroacetic acid (TCA), as previously described, and stored at $4{ }^{\circ} \mathrm{C}$ until analysis. The concentrations of substrate, and by-products in the filtered culture supernatants were determined with Enzytec Fluid kits purchased from R-Biofarm, as described by the manufacturer. Exoprotein concentration was determined by the Bradford protein assay (Pierce).

\section{Protein Sample Preparation, Trypsin In-gel Proteolysis, and Nano-LC-MS/MS Analysis}

Protein extraction and subsequent digestion were performed as previously described (Madeira et al., 2015). Extracellular and 
intracellular proteins from the 27 samples (biological triplicates from the three time conditions for the wild-type, $\triangle m s r A B$ and $\triangle m s r A B / \mathrm{pHT} 304-m s r A B$ strains) were resolved on NuPAGE ${ }^{\circledR}$ $4-12 \%$ Bis-Tris gels (Invitrogen) that were run for a short (about $3 \mathrm{~mm}$ ) electrophoretic migration using NuPAGE MES supplemented with NPAGE antioxidant as the running buffer (Hartmann and Armengaud, 2014). This avoids artefactual protein oxidation. For each of the 54 protein samples, the whole protein content was extracted as a single polyacrylamide band. The bands were subjected to proteolysis with sequencing grade trypsin (Roche) following the ProteaseMAX protocol (Promega), as previously described (De Groot et al., 2009; Clair et al., 2010). NanoLC-MS/MS experiments were performed using an LTQOrbitrap XL hybrid mass spectrometer (ThermoFisher) coupled to an Ultimate 3000 nRSLC system (Dionex, ThermoFisher; Dedieu et al., 2011; Madeira et al., 2015).

\section{Peptide and Protein Identification from MS/MS Datasets}

MS/MS spectra were searched against an in-house polypeptide sequence database corresponding to an improved annotation of the B. cereus ATCC 14,579 genome (Madeira et al., 2016a). The MASCOT Daemon search engine (version 2.3.02; Matrix Science) was used to search tryptic peptides as previously described (Dupierris et al., 2009; Madeira et al., 2016a). The mass spectrometry proteomics data have been deposited in the ProteomeXchange Consortium (http://proteomecentral. proteomexchange.org) via the PRIDE partner repository (http:// www.ebi.ac.uk/pride) with the dataset identifiers, PXD006169 and 10.6019/PXD006169 (exoproteome) and, PXD006205 and 10.6019/PXD006205 (cellular proteome).

\section{Label-Free Comparative Proteomics}

Analyses of changes of peptides and proteins in terms of abundance were achieved by comparing the spectral counts of proteins after voom transformation of abundance values using the $\mathrm{R}$ package LIMMA (Ritchie et al., 2015), as previously described (Madeira et al., 2016b). Data were normalized using the trimmed mean of $M$-values (TMM), implemented in the $\mathrm{R}$ package edgeR (Robinson et al., 2010). For quantitative comparisons, data were filtered to have two valid values in at least two biological replicates. Since we were specifically interested in the comparison between wild-type, $\triangle m s r A B$ mutant and the complemented strain $\triangle m s r A B / p H T-m s r A B$, we conducted differential analysis between WT and $\triangle m s r A B$, as well as $\triangle m s r A B$ and $\triangle m s r A B / \mathrm{pHT}-m s r A B$, and WT and $\triangle m s r A B / \mathrm{pHT}-$ $m s r A B$, individually. Differential protein and peptide abundances between WT and $\triangle m s r A B$, between $\triangle m s r A B$ and $\triangle m s r A B / p H T$ $m s r A B$, and between WT and $\triangle m s r A B /$ pHT- $m s r A B$ were considered significant at stringent $p$-values $(\leq 0.01)$. The results are presented as $\log _{2}$ fold-changes.

\section{Real-time RT-PCR and 5'RACE Assays}

Total RNA was prepared as described previously (Omer et al., 2015). Real-time RT-PCR was performed using the iScript ${ }^{\mathrm{TM}}$ One-Step RT-PCR kit with SYBR ${ }^{\circledR}$ Green following the manufacturer's protocol (Biorad). The $m s r A B$-specific primer pair used in this study was: $5^{\prime}$-TTCTGGTACACAGGTGGTC$3^{\prime}$ and 5'-AAAGCGTCCACTCTGCTCAA-3'. Gene expression was normalized by the $\triangle \Delta C T$ analysis. The $16 \mathrm{~s}$ rDNA was used as the reference gene in the calculations. The $16 \mathrm{~S}$ rDNAspecific primer pair was $5^{\prime}$-TCCAACTGATGGCGGAC-3' and $5^{\prime}$-TCACGCCCAGATTCTTTTTGC-3'. Rapid amplification of $5^{\prime}$ complementary cDNA ends ( $\left.5^{\prime} \mathrm{RACE}\right)$ was performed using the $5^{\prime} / 3^{\prime}$ RACE kit (Sigma). The $m s r A B$ specific primers SP1, SP2 and SP3 were: 5'-ATGTCCCGTCGTTTCTGAAC-3, 5' TCAAATGGCGAAACCATACA- $3^{\prime}$ and $5^{\prime}$-CCATACACCAGA AGCACCCT-3', repectively.

\section{Protease Activity Assay}

Sigma's non-specific protease activity assay was used to determine the protease activity of filtered culture supernatant. In this assay, casein acts as a substrate. Tyrosine, which is released on hydrolysis of casein by proteases, is able to react with Folin-Ciocalteu's reagent to produce a blue chromophore. The quantity of this chromophore was measured by means of its absorbance value by spectrophotometry. Absorbance values generated by the activity of the protease were compared to a standard curve, which was generated on the basis of known quantities of tyrosine. From the standard curve, the activity of protease samples was determined in units, corresponding to the amount in micromoles of tyrosine equivalents released from casein per minute. Experiments were performed twice for each of the 27 filtered culture supernatants. Statistical differences were evaluated by the Student's $t$-test.

\section{Long-Term Survival}

The survival of WT, $\triangle m s r A B$ mutant, and complemented $\triangle m s r A B$ mutant were determined as follows. After $24 \mathrm{~h}$ incubation at $37^{\circ} \mathrm{C}$ on glucose containing $\mathrm{MOD}$ medium, cultures were transferred to $4^{\circ} \mathrm{C}$. An aliquot of each culture was collected before and after 1, 2, 3, 4, and 5 days of exposure to $4^{\circ} \mathrm{C}$. Viable cells were determined by serial dilution of cultures in PBS, plating on LB agar, and incubation overnight $\left(37^{\circ} \mathrm{C}\right)$. Experiments were performed in triplicate. Statistical differences were evaluated by the Student's $t$-test.

\section{RESULTS}

\section{msrAB Expression Is Growth Phase Dependent}

Genome analyses of $B$. cereus ATCC 14579 identified an ORF (BC_5436) encoding a cytoplasmic protein annotated as MsrAB (NP_835097). This predicted cytoplasmic protein is composed of 321 amino acids and has a molecular weight of 36,938 Da. MsrAB and its gene $m s r A B$ are strongly conserved in members of the $B$. cereus group (data not shown). We mapped the transcriptional start site of $m s r A B$ by $5^{\prime}$ RACE. The transcriptional start site $(G)$ was located $23 \mathrm{nt}$ upstream of the translational start codon and was preceded by a region similar to $\sigma \mathrm{E}$ consensus-35 (TAATATG) and -10 (CATACTG) boxes separated by 13 nt. Furthermore, $m s r A B$ appeared to be followed by an inverted repeat $\left(\triangle \mathrm{G}^{\circ}=\right.$ $23.6 \mathrm{kcal} / \mathrm{mol}$ ) that may a transcriptional terminator (Figure S1). This indicates that $m s r A B$ may be transcribed as a single unit. 


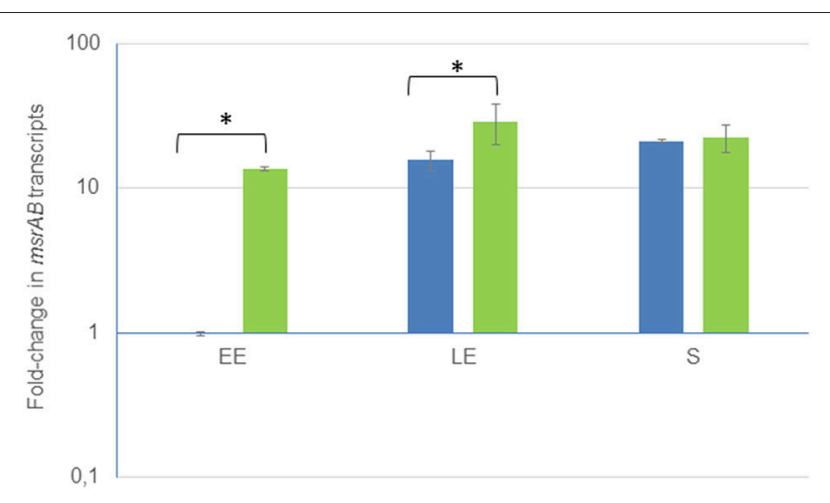

FIGURE 1 | Growth phase-dependent changes of msrAB transcript levels in wild-type (blue) and complemented $\triangle m s r A B / p H T 304 m s r A B$ (green) strains. Fold changes refer to the levels observed in early exponential (EE) phase cultures of the WT strains. Significant differences are indicated with one $p<$ 0.05) asterisks. LE, Late exponential growth phase; S, Stationary growth phase.

To determine whether there is any regulation of $m s r A B$, mRNA levels were measured at early exponential (EE), late exponential (LE) and stationary (S) growth phases. Figure 1 shows that there was about a 30 -fold increase in $m s r A B$ expression for cells harvested at the $S$ growth phase compared with the EE growth phase. B. cereus $m s r A B$ expression was thus maximal over the stationary phase. Similar stationary phase-induced expression of $m s r$ genes has been documented in several bacteria (Moskovitz et al., 1995; Vattanaviboon et al., 2005; Alamuri and Maier, 2006; Singh and Singh, 2012).

\section{MsrAB Contributes to $B$. cereus Respiratory Metabolism}

To investigate the role of $\mathrm{Msr} A B$ in $B$. cereus, we constructed a non-polar $\triangle m s r A B$ mutant and a $\triangle m s r A B$-complemented strain using a multicopy pHT304-based plasmid (Arantes and Lereclus, 1991). Expression of $m s r A B$ in the complemented strain was under the control of its own promoter. We did not detect $m s r A B$ mRNA by RT-PCR in the mutant, proving that the genomic disruption of the gene generated an $m s r A B$ null mutant. Figure 1 shows that $\operatorname{msr} A B$ was overexpressed in the strain $\triangle m s r A B / \mathrm{pHT} 304 m s r A B$ at the EE and LE growth phases. Therefore, $m s r A B$ expression level was not restored by complementation.

The growth characteristics of the three strains, $\triangle m s r A B$, $\triangle m s r A B / \mathrm{pHT} 304 m s r A B$, and the parental wild-type strain (WT), were determined under $\mathrm{pH}$-regulated aerobic respiratory conditions in synthetic MOD medium. Figure 2A shows that the lag phase was 2.5 -fold lower in the $\triangle m s r A B$ strain $(0.7 \pm$ $\left.0.1 \mathrm{~h}^{-1}\right)$ than in the $\triangle m s r A B / \mathrm{pHT} 304 m s r A B\left(1.8 \pm 0.9 \mathrm{~h}^{-1}\right)$ and WT $\left(1.9 \pm 0.2 \mathrm{~h}^{-1}\right)$ strains. Exponential growth kinetics were similar in the three strains for the first $6 \mathrm{~h}$. After this initial growth time, WT and $\triangle m s r A B$ cultures entered stationary phase. In contrast, $\triangle m s r A B / \mathrm{pHT} 304 m s r A B$ continued to grow and reached the stationary growth phase at a higher final biomass $\left(2.6 \pm 0.1\right.$ g. $\left.\mathrm{L}^{-1}\right)$ than $\triangle m s r A B\left(1.9 \pm 0.1\right.$ g. $\left.\mathrm{L}^{-1}\right)$ and WT $\left(1.8 \pm 0.2\right.$ g. $\left.\mathrm{L}^{-1}\right)$. The viabilities of $\triangle m s r A B$ and $\triangle m s r A B / p H T 304 m s r A B$ cells, harvested at $S$ growth phase, were similar to the viability of WT after 2 days but declined by more than 100 -fold after 5 days of storage at $4^{\circ} \mathrm{C}$ (Figure 2B). This suggests that $m s r A B$ expression impacts the metabolic activity of $B$. cereus cells at the end of growth (Chubukov and Sauer, 2014). Figure $2 \mathrm{C}$ shows that the $\triangle m s r A B$ and $\triangle m s r A B / \mathrm{pHT} 304 m s r A B$ strains consumed higher amounts of glucose than WT at the beginning of exponential growth. The $\triangle m s r A B / \mathrm{pHT} 304 m s r A B$ culture could be distinguished from the $\triangle m s r A B$ culture by continued glucose consumption between the $\mathrm{LE}$ and $\mathrm{S}$ growth phases (Figure $2 \mathrm{C}$ ). At the end of growth, $\triangle m s r A B / p H T 304 m s r A B$ consumed a higher level of glucose than $\triangle m s r A B$ and WT. During aerobic respiratory growth, glucose is catabolized into $\mathrm{CO}_{2}$ through the TCA cycle, and acetate is excreted as a by-product of overflow metabolism (Madeira et al., 2015; Duport et al., 2016). Figure 2D shows that $\triangle m s r A B$ cells, and to a lesser extent $\triangle m s r A B / \mathrm{pHT} 304 m s r A B$ cells, excreted higher amounts of acetate than WT cells during exponential growth. Acetate accumulation stopped at the LE growth phase in the $\triangle m s r A B$ and $\triangle m s r A B /$ pHT304msr $A B$ cultures while it continued to accumulate between the LE and $S$ growth phases in the WT culture. Taken together, these results suggest that $m s r A B$ expression impacts on the metabolic activity of $B$. cereus under aerobiosis.

To determine whether the alteration of glucose catabolism was associated with changes in extracellular protein production, extracellular proteins were extracted from culture supernatants of the three B. cereus strains, harvested during the EE, LE, and S growth phases (Madeira et al., 2015). Figure 3A shows that the $\triangle m s r A B$ culture supernatant accumulated a higher amount of exoproteins than that of WT at the LE phase. However, $\triangle m s r A B$ supernatant had 50 and $90 \%$ fewer exoproteins in the EE and $S$ growth phases, respectively, compared with WT. This decreased exoprotein concentration could have resulted from a higher protease activity in the $\triangle m s r A B$ culture supernatant. To test this hypothesis, we quantified the protease activity of the $\triangle m s r A B$, $\triangle m s r A B / \mathrm{pHT} 304 m s r A B$ and WT culture supernatants against casein. Figure $3 \mathbf{B}$ shows that the $\triangle m s r A B$ culture supernatant sustained a higher protease activity than WT, markedly in the EE and $\mathrm{S}$ growth phases. These changes in protease activity were only partially rescued in $\triangle m s r A B / \mathrm{pHT} 304 m s r A B$. However, unlike $\triangle m s r A B /$ pHT304ms $A B$, there was no correlation between the protease activity and the amount of exoproteins in $\triangle m s r A B$ at LE phase (Figure 3A). This indicates that changes in $m s r A B$ expression could be selective for certain extracellular proteases.

\section{MsrAB Modulates the Proteome Profile of B. cereus}

To determine if altered metabolism in $\triangle m s r A B$ and $\triangle m s r A B /$ pHT304msr $A B$ was associated with cellular and exoproteome profile changes, we quantified protein abundance level differences between $\triangle m s r A B, \triangle m s r A B / \mathrm{pHT} 304 m s r A B$, and WT cells in the EE, LE and $S$ growth phases. Exoproteome and cellular proteome samples were prepared from supernatant cultures and whole-cell lysates, respectively. A total of 200,746 and 71,676 MS/MS spectra were recorded from cellular proteome and exoproteome samples, respectively. A total of 922 proteins were identified in the cellular proteome (Table S1) and 371 

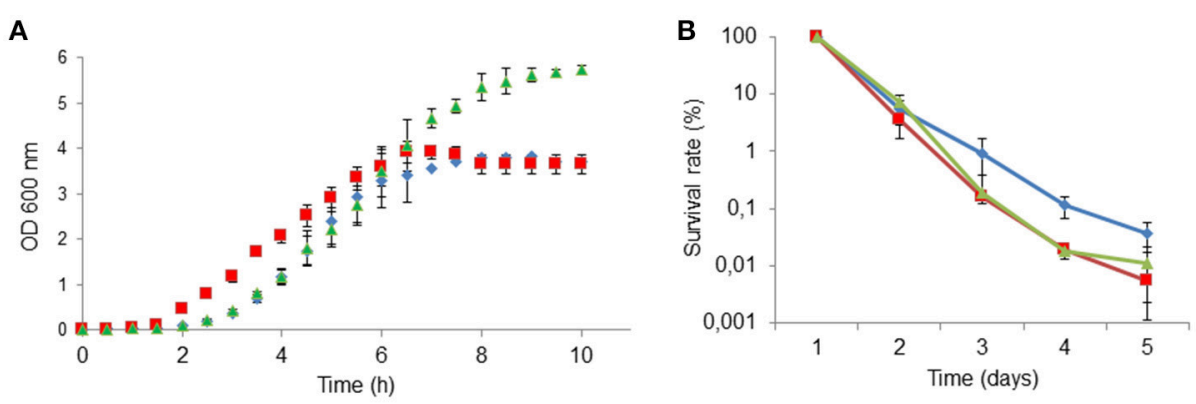

C
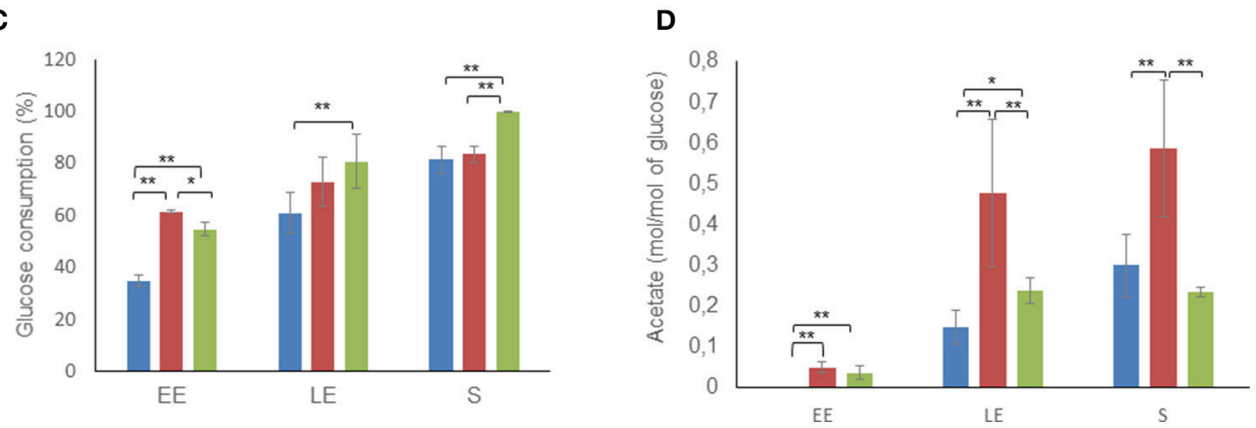

FIGURE 2 | Altered growth and long-term survival of $\triangle m s r A B$ mutant cells and complemented $\triangle m s r A B / p H T 304 m s r A B$ cells. (A) Growth curves of WT (blue), $\triangle m s r A B$ (red) and $\triangle m s r A B / p H T 304 m s r A B$ (green) cells in pH-regulated batch cultures under aerobiosis. (B) Long-term survival of WT (blue), $\triangle m s r A B$ (red) and $\triangle m s r A B / p H T 304 m s r A B$ (green) cells after growth under aerobiosis. (C) Glucose consumption of WT (blue), $\triangle m s r A B$ (red) and $\triangle m s r A B / p H T 304 m s r A B$ (green) cells. (D) Acetate production of WT (blue), $\triangle m s r A B$ (red) and $\triangle m s r A B / p H T 304 m s r A B$ (green) cells. Significant differences are indicated with one $(p<0.05)$ or two $(p<$ 0.01) asterisks.

proteins were identified in the exoproteome (Table S2), based on the confident detection of at least two different peptides. A twosample $t$-test was then conducted separately between WT and $\triangle m s r A B$, and between $\triangle m s r A B$ and $\triangle m s r A B /$ pHT304msr $A B$. All proteins with a $p \leq 0.01$ and at least a 2 -fold change $\left(\log _{2}\right.$ fold-change $\geq 1$ ) were considered to be differentially modulated in terms of abundance. A total of 64 and 78 proteins were found to vary in abundance in $\triangle m s r A B$ compared with WT in the cellular proteome and exoproteome fractions, respectively. The majority $(80 \%)$ of these proteins were not rescued in $\triangle m s r A B / p H T 304 m s r A B$ (data not shown). The Venn diagrams presented in Figure 4 show the growth phase distribution of the identified proteins. Less than $2 \%$ of proteins showed abundance level changes in all three growth stages, indicating that $m s r A B$ modulates $B$. cereus cellular and exoproteome mainly in a growth phase-dependent manner. The impact of msrAB disruption appeared to be more important at the $\mathrm{LE}$ and $\mathrm{S}$ than the $\mathrm{EE}$ growth phase in the cellular proteome (Figure 4A), according to its expression (Figure 1).

\section{Cellular Proteins}

Table 1 lists the identities and putative functions of the cellular proteins differentially produced in $\triangle m s r A B$ compared with WT. In the EE phase, three proteins impacted by $m s r A B$ disruption were classified as carbohydrate metabolism enzymes. The glycolytic enzyme, Tpi (triose phosphate isomerase), and the two TCA enzymes, Mqo (malate:quinone oxidoreductase) and FumB (fumarate hydratase), were less abundant in $\triangle m s r A B$ than WT. Tpi catalyzes the interconversion of dihydroacetone phosphate (DHAP) and glyceraldehyde-3-phosphate to prevent DHAP accumulation. It has been shown that a reduction of Tpi activity redirected the carbon flux from glycolysis to the pentose phosphate pathway (PPP), which provides the redox power for antioxidant systems (Ralser et al., 2007). FumB catalyzes the reversible hydration of fumarate to malate, and Mqo oxidizes malate to oxaloacetate and reduces quinone via a onetransfer electron reaction (Kabashima et al., 2013). By decreasing FumB and Mqo levels, $\triangle m s r A B$ cells can thus decrease TCA activity, and consequently respiratory chain activity and ROS production. The reduction of respiratory chain capacity could be compensated by increasing glycolytic flux and increasing overflow metabolism (acetate excretion), as observed in Figure 2. Only one stress response-related protein (USP) was shown to be differentially produced in $\triangle m s r A B$ at EE phase. As recently reported, USP may function as a protein regulator of downstream effectors of nucleotide-binding protein cycling. This activity depends on the energy status (ATP level) of the cells (Banerjee et al., 2015). A decrease in the UPS abundance level in $\triangle m s r A B$ could thus reflect a change in ATP availability and/or demand at EE phase. $\triangle m s r A B$ also sustained a higher level of RibD whatever the growth phase. The gene encoding RibD belongs to the putative operon ribDEAH, which encodes RibD, a pyrimidine deaminase/reductase, RibE, the $\alpha$-subunit of riboflavin synthase, RibA, the GTP cyclohydrolase/3,4-dihydroxy 2-butanone 4phosphate $(3,4-\mathrm{DHBP})$ synthase, and $\mathrm{RibH}$, the $\beta$-subunit of riboflavin (RibH). These enzymes form a pathway that produces 

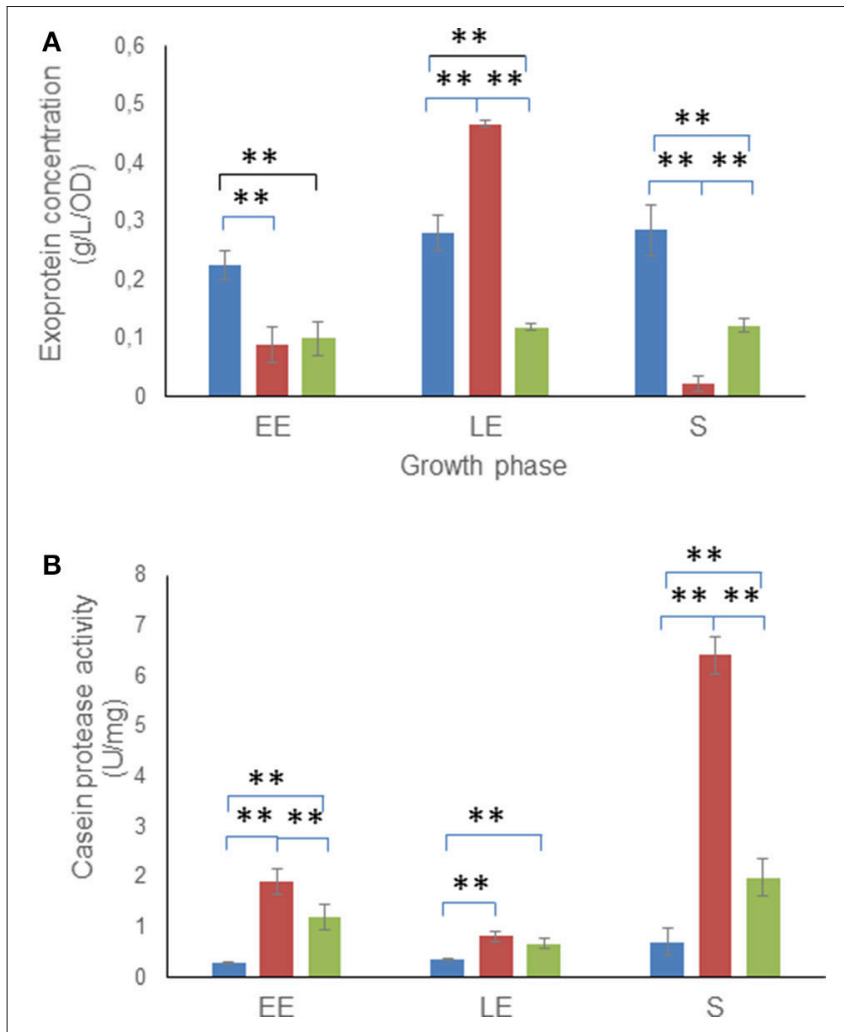

FIGURE 3 | Exoproteome concentration and protease assay. Concentrations (A) and casein proteolytic activity (B) are indicated for total extracellular proteins of WT (blue), $\triangle m s r A B$ (red) and $\triangle m s r A B / p H T 304 m s r A B$ (green) cells. Error bars represent the standard deviation from two independent measures for each biological triplicate. Significant differences $(p<0.01)$ between WT, $\triangle m s r A B$ and $\triangle m s r A B / p H T 304 m s r A B$ strains are indicated with two asterisks.

one riboflavin molecule from GTP and ribulose-5-phosphate (Vitreschak et al., 2002). RibA and RibH were more highly produced in $\triangle m s r A B$ than in WT at LE growth phase and RibE was more highly produced at $S$ growth phase. Together these results suggest the increased production in $\triangle m s r A B$ of riboflavin, which is known to be an element of antioxidant defense (Abbas and Sibirny, 2011). One stress-related protein, named AcpD (annotated as an azoreductase), which was not detected in WT cells (Table S1), was significantly induced at both LE and S growth phases in $\triangle m s r A B$ cells. AcpD is a putative FMN$\mathrm{NAD}(\mathrm{P}) \mathrm{H}$-dependent quinone oxidoreductase that catalyzes the two-electron reduction of quinones to quinols. This protein could play an important role in managing oxidative stress in the absence of $m s r A B$ by maintaining the reduced antioxidant form of quinone (Ross et al., 2000; Ryan et al., 2014). Several proteins related to the biosynthesis of amino acids were upregulated at the $\mathrm{LE}$ and $\mathrm{S}$ phases. This suggests that an increase in the intracellular content of these amino acids may be part of the adaptive response to the lack of MsrAB.

A protein was considered validated when at least two different peptides were found in the same sample. We found only one peptide assigned to MsrAB and did not validate its presence in the cellular proteome. To determine whether MsrAB is a

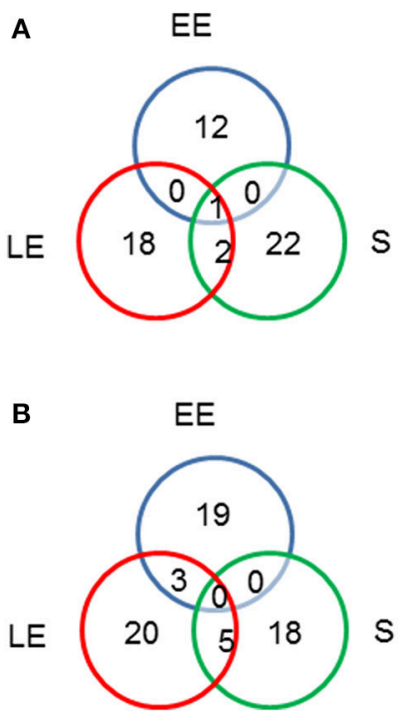

FIGURE 4 | Distribution of proteins showing abundance level changes $p<$ $0.05)$ between wild-type and $\triangle m s r A B$ mutant strains. Venn diagrams showing the number of regulated intracellular proteins $(\mathbf{A})$ and exoproteins $(\mathbf{B})$ in the $\triangle m s r A B$ mutant in the early exponential (EE), late exponential (LE) and stationary (S) growth phases.

true cellular protein, we carried out further analyses using a Q-exactive HF mass spectrometer. Five and 19 peptides assigned to MsrAB were detected in the cellular proteome of WT and $\triangle m s r A B /$ pHT304msr $A B$, respectively, at LE and $S$ growth phases (Figure S1) No peptide was detected in the exoproteome, proving that MsrAB is cytoplasmic.

\section{Exoproteome}

Table 2 lists the exoproteins that were considered as differentially produced in $\triangle m s r A B$ supernatant. The majority of the metabolism and stress/detoxification-related proteins were less abundant in $\triangle m s r A B$ compared with WT, regardless of growth phase. These proteins were predicted to be cytosolic and, accordingly, we found that they were more abundant in the cellular proteome compared with the exoproteome (Table S3). In contrast, the majority of the cell wall/surface-associated proteins, transporters and degradative/adhesin proteins, which were predicted to be secreted proteins, were increased in $\triangle m s r A B$ compared with WT, especially at the EE and LE growth phases. This suggests that msrAB deletion could favor the accumulation of some secreted exoproteins at the expense of cytosolic proteins. Interestingly, two predicted secreted foldases, PrsA1 and PsrA2, showed significant increases in their abundance levels in $\triangle m s r A B$, especially at LE growth phase. PrsA1 and PrsA2 have been predicted to function as peptidyl-prolyl isomerases at the bacterial membrane-cell wall interface, to assist in the folding and stability of exported proteins (Vitikainen et al., 2004). In addition, we noted increased abundance levels of a bacterial type I signal peptidase protein (SPase) in $\triangle m s r A B$ compared with WT at LE phase. SPases function at the terminal step of the general secretory pathway by releasing translocated proteins from the 
TABLE 1 | Cellular proteins with significant abundance level changes ( $\log _{2} \mid$ fold-change $\left.>1, p<0.01\right)$ in $\triangle m s r A B$ compared with WT.

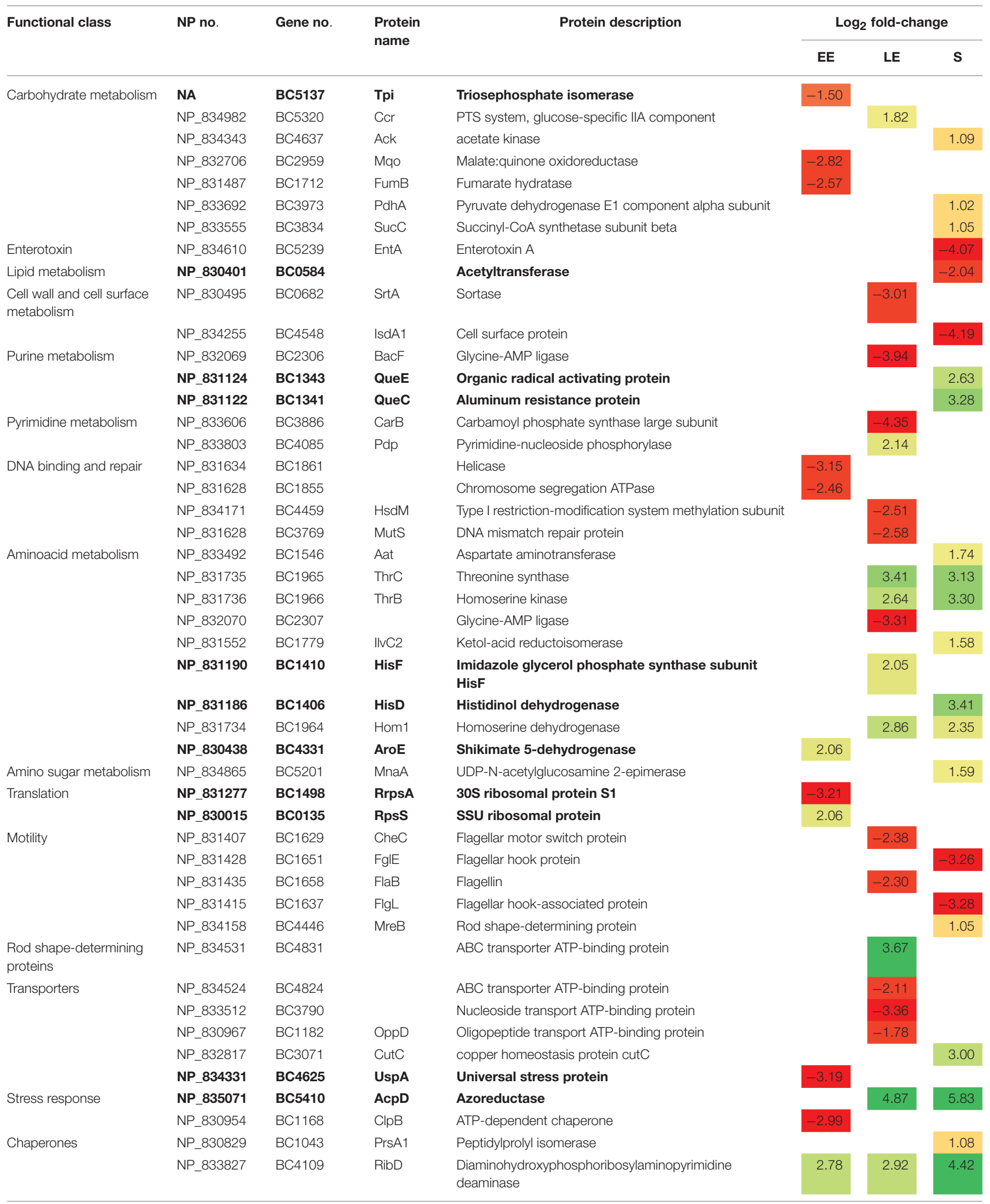


TABLE 1 | Continued

\begin{tabular}{|c|c|c|c|c|c|c|c|}
\hline \multirow[t]{2}{*}{ Functional class } & \multirow[t]{2}{*}{ NP no. } & \multirow[t]{2}{*}{ Gene no. } & \multirow{2}{*}{$\begin{array}{l}\text { Protein } \\
\text { name }\end{array}$} & \multirow[t]{2}{*}{ Protein description } & \multicolumn{3}{|c|}{$\log _{2}$ fold-change } \\
\hline & & & & & EE & LE & $\mathbf{S}$ \\
\hline \multirow[t]{4}{*}{ Riboflavin biosynthesis } & NP_833829 & BC4111 & RibA & $\begin{array}{l}\text { Bifunctional 3,4-dihydroxy-2-butanone 4-phosphate } \\
\text { synthase }\end{array}$ & & 2.87 & \\
\hline & NP_833828 & BC4110 & RibE & Riboflavin synthase subunit alpha & & & 2.20 \\
\hline & NP_833830 & BC4112 & $\mathrm{RibH}$ & Riboflavin synthase subunit beta & & 1.68 & \\
\hline & NP_833832 & BC4114 & BioB & Biotin synthase & & & 3.40 \\
\hline Biotin biosynthess & NP_831123 & BC1342 & & 6-pyruvoyl tetrahydrobiopterin synthase & 2.16 & & \\
\hline Folate biosynthesis & NP_833540 & BC3819 & Dxr2 & 1-deoxy-D-xylulose 5-phosphate reductoisomerase & 2.75 & & \\
\hline $\begin{array}{l}\text { Terpenoid backbone } \\
\text { biosynthesis }\end{array}$ & NP_831099 & $\mathrm{BC} 1317$ & PhaB & Acetoacetyl-CoA reductase & -2.53 & & \\
\hline \multirow[t]{10}{*}{ Uncategorized } & NP_829927 & BC0025 & & Unknown & & 2.67 & \\
\hline & NP_832675 & BC2927 & & Prolyl endopeptidase & & & 4.18 \\
\hline & NP_831667 & BC1894 & & Phage protein & -2.84 & & \\
\hline & NP_831673 & BC1901 & & phage protein & & & -2.43 \\
\hline & NP_834610 & BC4938 & & NADH dehydrogenase & & 2.03 & \\
\hline & NP_834043 & BC0622 & & L-threonine 3-dehydrogenase & & & 2.14 \\
\hline & NP_830802 & BC1016 & & Unknown & & 3.04 & \\
\hline & NP_834559 & BC4860 & & Unknown & & & -1.97 \\
\hline & NP_829986 & BC0105 & & Unknown & & & 1.87 \\
\hline & NP_834083 & BC4371 & & Unknown & & & 1.57 \\
\hline
\end{tabular}

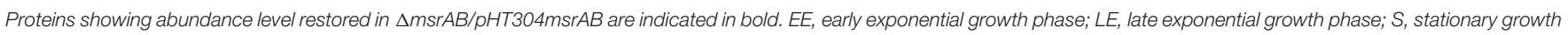
phase. NA, Not Annotated. Green and red highlights indicate increased and decreased protein levels, respectively.

cytoplasmic membrane at a defined cleavage site (Craney et al., 2015). This Spase could thus function in conjunction with PrsA proteins to sustain a higher secretion level of some proteins (Alonzo et al., 2011).

Several proteins classified as degradative enzymes showed higher abundance levels in $\triangle m s r A B$ compared with WT (Table 2) and could contribute to the high protease activity of the $\triangle m s r A B$ extracellular milieu (Figure 3B). Interestingly, we showed that the abundance level of Npr600, a predicted bacillolysin, was restored in $\triangle m s r A B / p H T 304 m s r A B$ at LE phase. Npr600 could thus be a major contributor to the protease activity of $\triangle m s r A B$ at LE phase (Altincicek et al., 2007).

\section{msrAB Regulates the Dynamic of the Met(O) Content of the $B$. cereus Proteome}

We identified peptides with oxidized Met in $\triangle m s r A B$, $\triangle m s r A B / \mathrm{pHT} 304 m s r A B$, and WT, in both the cellular proteome and the exoproteome at EE, LE, and $S$ growth phases, as previously described (Madeira et al., 2015). The Met(O) content of both the cellular proteome and the exoproteome was estimated by comparing the number of $\operatorname{Met}(\mathrm{O})$ to the total number of Met residues identified in each of the three biological samples obtained for each growth phase in each of the three strains (Tables S4, S5). Figure 5 shows that the $\operatorname{Met}(\mathrm{O})$ content of WT and $\triangle m s r A B / p H T 304 m s r A B$ decreased similarly in the cellular proteome (Figure 5A) and exoproteome (Figure 5B) during growth. The $\operatorname{Met}(\mathrm{O})$ content of the $\triangle m s r A B$ intracellular proteome also decreased during exponential growth and was lower than the $\operatorname{Met}(\mathrm{O})$ content of WT at LE phase and higher at $\mathrm{S}$ growth phase. More importantly, the $\operatorname{Met}(\mathrm{O})$ content of the $\triangle m s r A B$ exoproteome remained constant during growth and accounted for $38 \pm 3 \%$ of total Met residues. Taken together, these results indicate that $\mathrm{MsrAB}$ regulates the dynamic of the $\mathrm{Met}(\mathrm{O})$ content of the proteome, especially at the exoproteome level.

To identify peptides exhibiting significant differences in Met $(\mathrm{O})$ content in $\triangle m s r A B$ compared with WT, we conducted a $t$-statistical analysis. For a robust analysis, we considered a peptide as containing an oxidized Met residue when it was identified in at least two biological replicates. The lists of intra- and extracellular peptides showing significant $\operatorname{Met}(\mathrm{O})$ level changes ( $\log _{2}$ fold-change $>1$ and $\left.p \leq 0.01\right)$ according to growth phase are presented in Tables 3, 4 .

\section{Cellular Proteome}

The number of peptides with $\operatorname{Met}(\mathrm{O})$ content changes was lower at the EE (6) than the LE (13) and S (19) growth phases. Only one peptide, a RibH-related peptide, showed similar changes in the two growth phases (Table 3). At the EE growth phase, we noted that the subunit E2 of the pyruvate dehydrogenase complex (PdhC), which interconnects glycolysis with acetate metabolism, had one peptide with a decreased $\operatorname{Met}(\mathrm{O})$ level in EE phase. This could impact the activity of this enzyme and contribute to the metabolic perturbation observed in $\triangle m s r A B$ at EE phase (Figure 2; Martin et al., 2005). At the LE growth phase, the majority of the identified peptides showed a lower Met(O) content in $\triangle m s r A B$ compared with WT at LE phase. This is consistent with the results presented in Figure 4. At 
TABLE 2 | Exoproteins with significant abundance level changes (|log2|fold-change $>1, p<0.01$ ) in $\triangle m s r A B$ compared with WT.

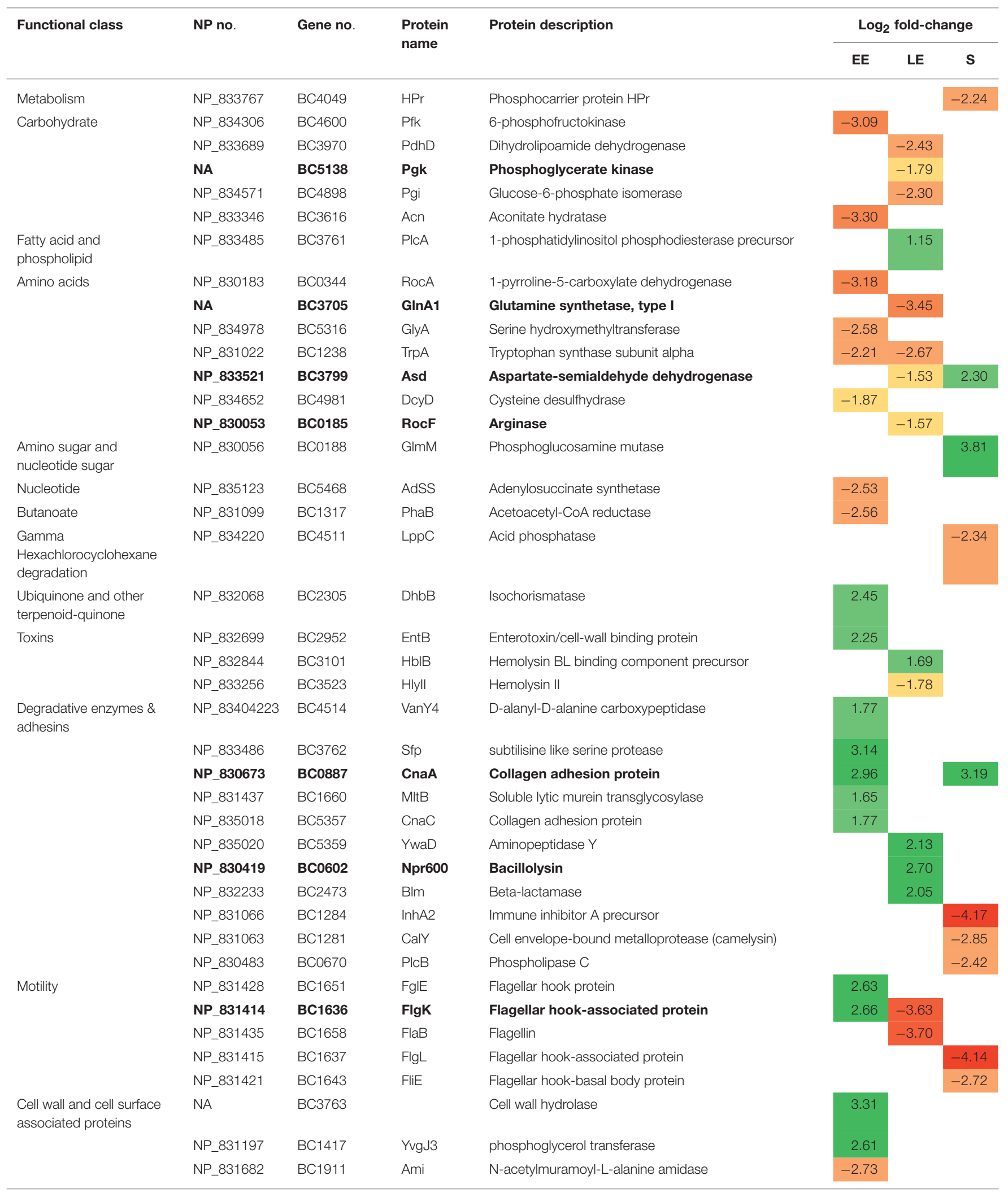


TABLE 2 | Continued

\begin{tabular}{|c|c|c|c|c|c|c|c|}
\hline Functional class & NP no. & Gene no. & $\begin{array}{l}\text { Protein } \\
\text { name }\end{array}$ & Protein description & \multicolumn{3}{|c|}{$\log _{2}$ fold-change } \\
\hline & NP_832677 & BC2929 & PgdA & Peptidoglycan $\mathrm{N}$-acetylglucosamine deacetylase & & 2.67 & \\
\hline & NP_831846 & BC2078 & & Hypothetical Membrane Spanning Protein & & & -3.07 \\
\hline & NP_832595 & BC2846 & DltD & Protein dltD precursor & & & -2.25 \\
\hline & NP_833266 & ВC3533 & VanW & Vancomycin B-type resistance protein vanW & 1.67 & & \\
\hline Protein export & NP_832816 & ВС3070 & SipA & Signal peptidase I & & 2.04 & \\
\hline \multirow[t]{3}{*}{ Transport } & NP_831789 & BC2021 & ZnuA & High-affinity zinc uptake system protein & 1.48 & & \\
\hline & NP_834656 & BC4985 & & $\mathrm{ABC}$ transporter substrate-binding protein & & & -3.93 \\
\hline & NP_830083 & BC0215 & OppA2 & Oligopeptide-binding protein oppA & & & -2.53 \\
\hline \multirow{2}{*}{ Stress/detoxification } & NP_833272 & ВС3539 & CspB & Cold shock protein & & -5.13 & -3.92 \\
\hline & NP_830215 & ВС0376 & AhpF & Alkyl hydroperoxide reductase subunit $F$ & & -1.99 & \\
\hline \multirow[t]{3}{*}{ Protein folding } & NP_830947 & BC1161 & PrsA2 & Peptidylprolyl isomerase & & 2.80 & \\
\hline & NP_830829 & BC1043 & PrsA1 & Peptidylprolyl isomerase & & 2.57 & \\
\hline & NP_834192 & BC4480 & Tig & Trigger factor & & & -2.14 \\
\hline \multirow[t]{4}{*}{ Translation } & NP_830029 & BC0149 & RpmD & 50 S ribosomal protein L30 & 1.30 & & \\
\hline & NP_833528 & ВС3806 & $\mathrm{RpsO}$ & 30 S ribosomal protein S15 & & & -2.38 \\
\hline & NP_830008 & BC0128 & FusA & Elongation factor $\mathrm{G}$ & & -2.59 & \\
\hline & NP_830009 & BC0129 & Tuf & Elongation factor $\mathrm{Tu}$ & & -2.79 & 2.95 \\
\hline Transcriptional regulators & NP_830591 & BC0801 & LytR2 & LytR family transcriptional regulator & 1.98 & & \\
\hline \multirow{5}{*}{ Uncategorized } & NP_832991 & ВС3251 & & Unknown & & -2.71 & \\
\hline & NP_835021 & BC5360 & & Unknown & & 2.05 & \\
\hline & NP_830068 & BC0200 & & Unknown & & 1.64 & \\
\hline & NP_832874 & ВС3133 & & Unknown & & & -1.86 \\
\hline & NP_833260 & ВС3527 & & Unknown & & 1.75 & \\
\hline
\end{tabular}

Exoproteins with abundance level restored in $\triangle \mathrm{msr} A B / \mathrm{pHT} 304 \mathrm{~ms} \mathrm{AB}$ are indicated in bold. EE, early exponential growth phase; LE, late exponential growth phase; S, stationary growth phase. NA, Not Annotated. Green and red highlights indicate increased and decreased protein levels, respectively.

the $S$ growth phase, the majority of the identified peptides $(12 / 18)$ showed a higher $\operatorname{Met}(\mathrm{O})$ level in $\triangle m s r A B$ compared with WT. Among these 12 peptides, 6 are RibH-related peptides. Two of these six peptides had their $\operatorname{Met}(\mathrm{O})$ level restored in $\triangle m s r A B / \mathrm{pHT} 304 m s r A B$ (Table 3). RibH contains four Met residues: all of these were more highly oxidized in $\triangle m s r A B$ than in WT at the S growth phase and two were more highly oxidized in $\triangle m s r A B$ than in $\triangle m s r A B / \mathrm{pHT} 304 m s r A B$. RibH is thus a target of MsrAB activity and the major contributor to the difference observed between $\triangle m s r A B$ and WT on the one hand, and $\triangle m s r A B$ and $\triangle m s r A B / \mathrm{pHT} 304 m s r A B$ on the other, at the $\mathrm{S}$ growth phase (Figure 5).

\section{Exoproteome}

Table 4 shows that peptides with differential $\operatorname{Met}(\mathrm{O})$ contents belong to 21 proteins, including eight toxin-related proteins. The LE growth phase sustained the highest number of peptides with increased $\operatorname{Met}(\mathrm{O})$ levels (10); the majority of these peptides $(9 / 10)$ had their $\operatorname{Met}(\mathrm{O})$ level restored in $\triangle m s r A B / \mathrm{pHT} 304 m s r A B$, indicating a direct impact of MsrAB. Among the proteins with increased oxidation of Met residues were the degradative enzyme, $\mathrm{PlcA}$, the flagellin, FlaA, and the four toxin-related proteins, NheA, HblB, EntC and EntD. Only PlcA and HblB showed increased abundance levels at LE growth phase (Table 2). FlaB was the protein for which we detected the largest number of 


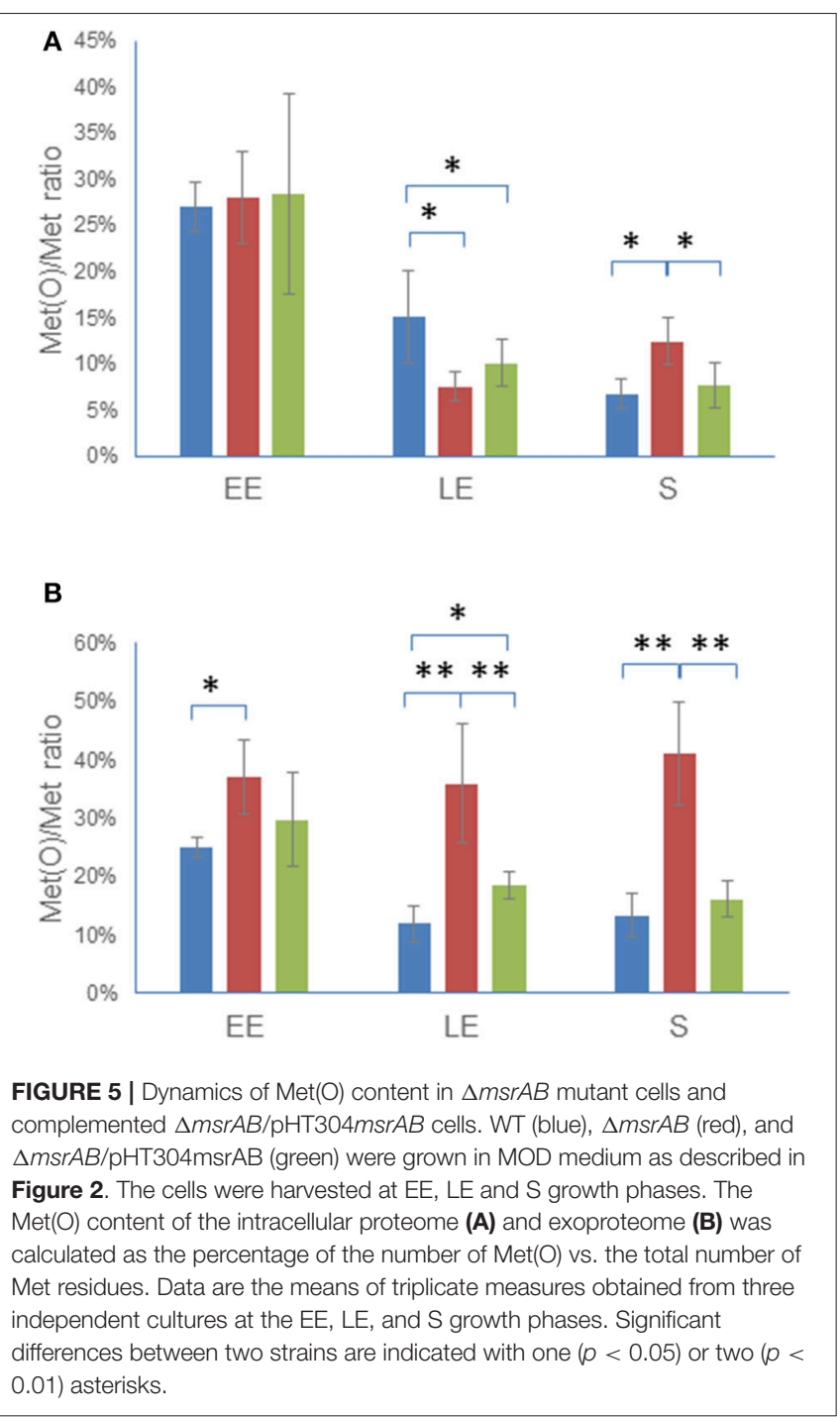

Met $(\mathrm{O})$ peptides and Met residues with differential oxidation (7 Met residues). All of these residues were less oxidized in $\triangle m s r A B$ compared with WT at LE phase. In addition, we observed that FlaB was less abundant in $\triangle m s r A B$ at LE phase (Table 2). The loss of Met-oxidized peptides could thus be due to degradation of protein copies. This is possibly also the case for HlyII (Tables 2, 4). In $S$ growth phase, the peptides with increased $\operatorname{Met}(\mathrm{O})$ content belong to the putative $\mathrm{N}$-acetylmuramoyl-L-alanine amidase $\mathrm{CwlC}$ and the toxin-related EntA, HblB, and HblL2. All HblL2bound Met were not equally susceptible to $m s r A B$ disruption, as one Met residue was more oxidized at the $S$ growth phase, one was more oxidized at the LE growth phase and two were less oxidized, especially at the EE growth phase. Taken together, the results indicate that MsrAB regulates the dynamic of the $\operatorname{Met}(\mathrm{O})$ level of the exoproteome by controlling the $\operatorname{Met}(\mathrm{O})$ level of target peptides in a growth phase- and protein-dependent manner. Importantly, our results indicate that virulence factors such enterotoxins, degradative enzymes, and flagella components are MsrAB targets.

\section{DISCUSSION}

Methionine (Met) residues in proteins and their recycling by methionine sulfoxide reductases (Msrs) are part of the antioxidant system produced by aerobic microorganisms. The antioxidant system keeps a steady-state control over ROS production-detoxification (Levine et al., 1996; Kim, 2013). The tight regulation of ROS production and detoxification represents the basis for the maintenance of an appropriate redox homeostasis, which is central for growth.

While Met residues in cellular proteins are well-recognized as antioxidants, the relative importance of Met residues in extracellular proteins has hitherto not been established. In this study, we used next-generation proteomics on wild-type B. cereus and an MsrAB mutant to demonstrate that Met residues in exoproteins could be reversibly oxidized to $\operatorname{Met}(\mathrm{O})$, probably before their exportation. In addition, we provide the first evidence that $B$. cereus can modulate its capacity and specificity for protein export (secretion) through the growth phasedependent expression of the methionine sulfoxide reductaseencoding gene, $m s r A B$.

As reported for other $m s r$ genes in several bacteria, $m s r A B$ expression is lower in exponentially grown $B$. cereus cells than in growth-arrested cells. The low level of $m s r A B$ expression is probably sufficient to maintain a proper activity of the antioxidant system during exponential growth phase. The increased expression of $m s r A B$ at the end of growth would serve to minimize the accumulation of oxidative damage on ROS-affected molecules (Dukan and Nystrom, 1999). However, the expression level of $m s r A B$ in B. cereus cells is not by itself sufficient to prevent premature growth arrest under full aerobic conditions as growth can be prolonged by overproducing $m s r A B$. In WT cells, premature growth arrest allows the cells to survive for extended time periods, suggesting that MsrAB could be a regulator of normal lifespan of B. cereus (Koc et al., 2004).

Considering the primary antioxidant function of MsrAB, variation of other antioxidant proteins was expected in MsrABdeficient cells as a part of putative compensatory mechanisms or due to altered interactions with MsrAB (Alamuri and Maier, 2006). We observed abundance level changes in antioxidant proteins, mainly at LE phase, due to the lack of protection normally conferred by the high expression of $m s r A B$. Neutralizing ROS without quelling its production may prove to be onerous to $B$. cereus. Our results indicate that $B$. cereus reprograms its proteome to both counteract and inhibit the formation of ROS in msrAB-deficient cells. This proteome modification leads to novel metabolic networks that allow the alleviation of TCA cycle activity, the main metabolic network that supplies NADH for oxidative phosphorylation. When the machinery involved in oxidative phosphorylation is severely impeded by the ROS challenge, glucose uptake is enhanced to satisfy the ATP need by substrate level phosphorylation. Increased carbon flow also maintains constant levels of glycolytic intermediates as macromolecular precursors and boosts carbon flow through the PPP, which produces large amount of NADPH, a key molecule that is used to 


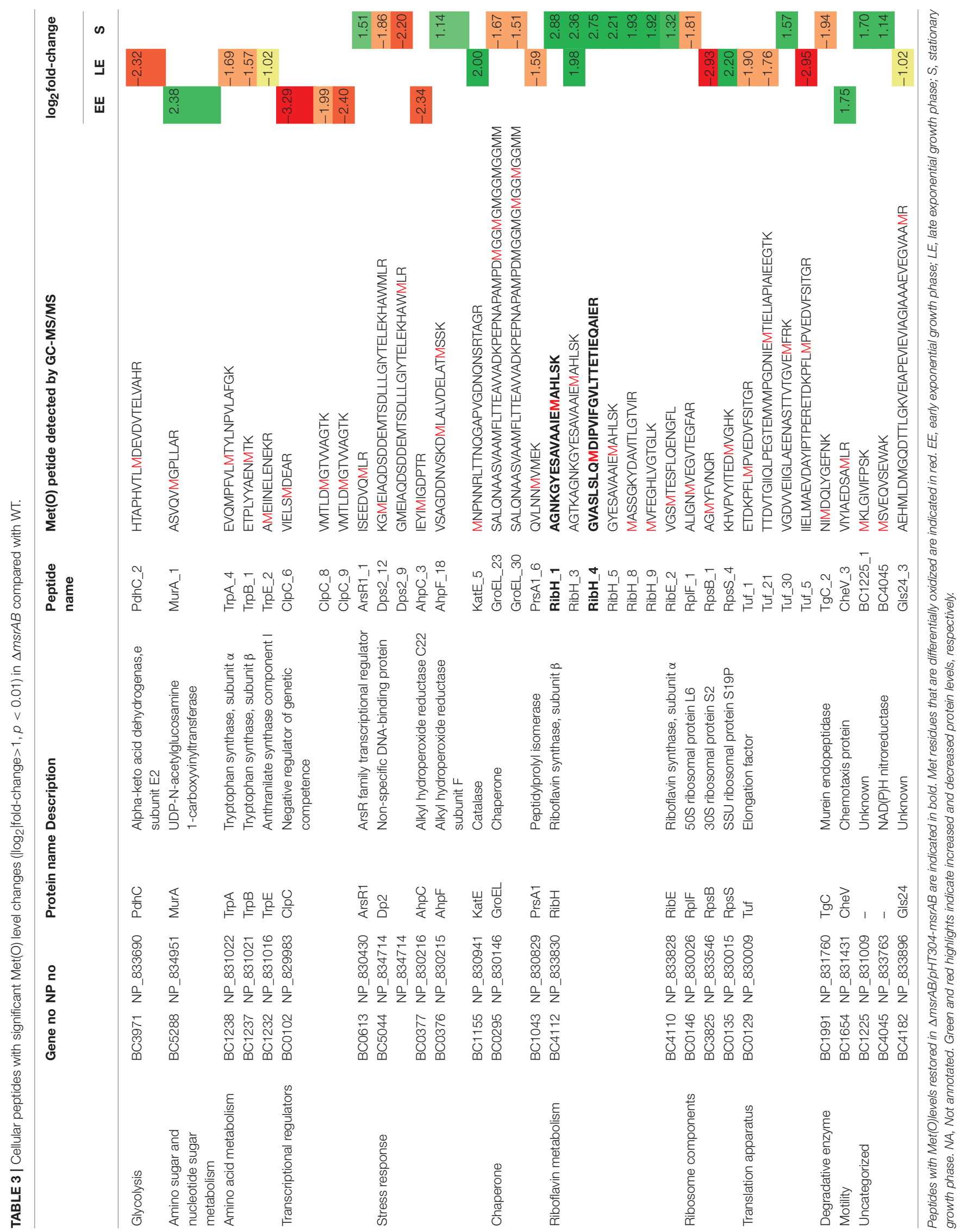




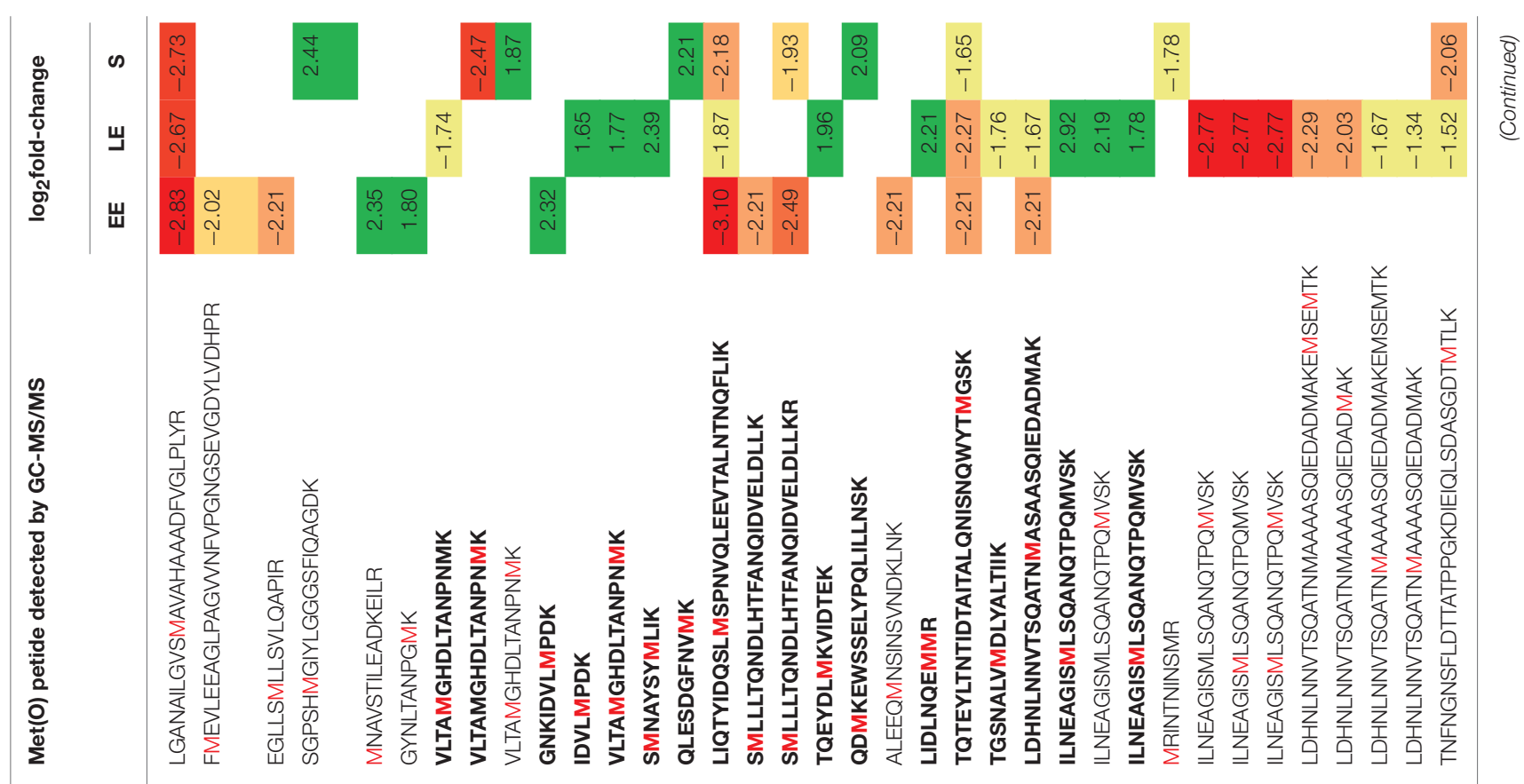

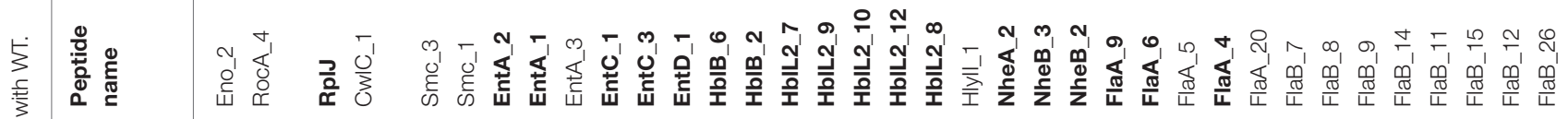

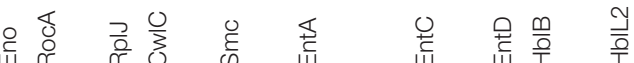

王离离离

$\frac{\mathbb{\pi}}{\square}$

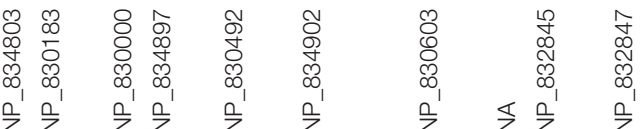

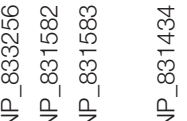

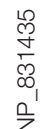

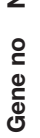

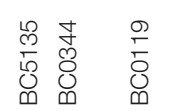

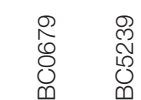

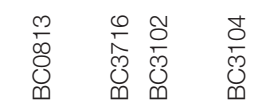

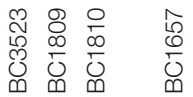

$\infty$
10
0
0
0

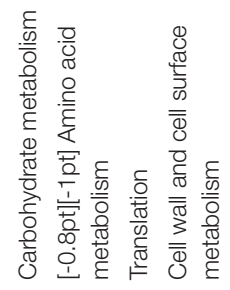




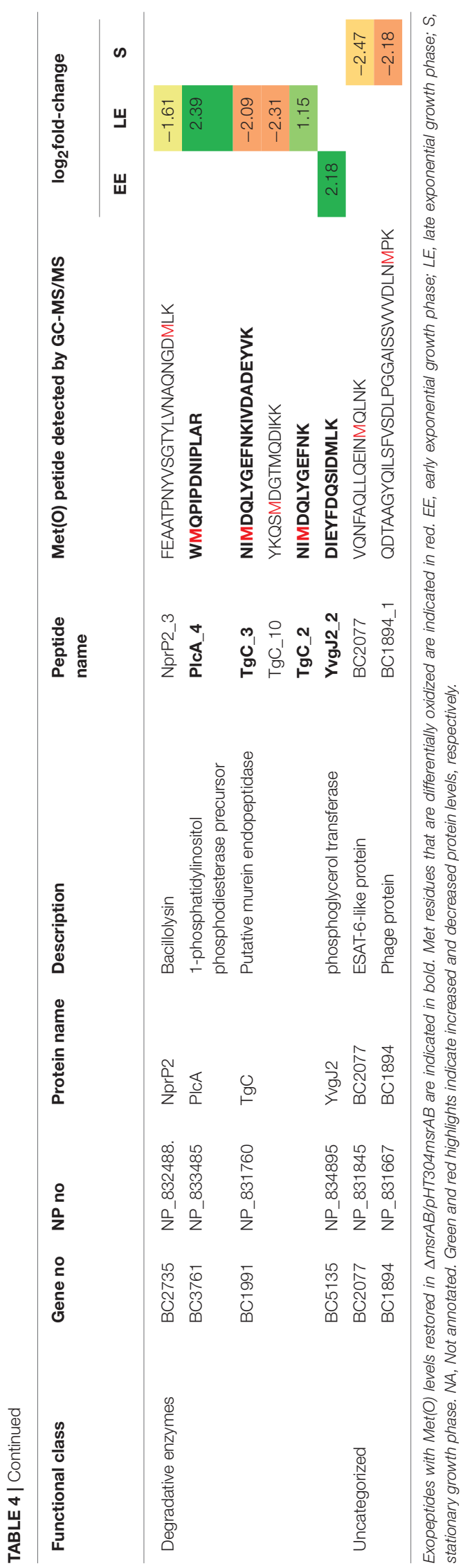

drive anabolic processes and provides the reducing power to the antioxidative system. PPP is also required for synthesis of the low-molecular-weight bacillithiol (Richardson et al., 2015).

When $m s r A B$ is disrupted, B. cereus accumulates a higher level of $\operatorname{Met}(\mathrm{O})$ exoproteins in the growth medium and a lower level of $\operatorname{Met}(\mathrm{O})$ cellular protein at LE phase. This suggests that B. cereus can overcome the lack of MsrAB activity by promoting export of $\operatorname{Met}(\mathrm{O})$ proteins to maintain intracellular redox homeostasis. Our results indicate that MsrAB deficiency promotes export of some proteins by directly or indirectly modulating the efficiency of the translocation/secretion machinery. Among these proteins are proteases, which probably contribute to the high proteolytic activity of the growth medium of $m s r A B$ deficient cells and the highly reduced exoprotein level at the end of growth (Figure 3). Upregulation of proteases has been reported in several bacteria as part of the secretion stress response, which is induced to prevent the accumulation of misfolded proteins outside the cytoplasmic membrane (Westers et al., 2006). MsrAB deficiency leads to the accumulation of oxidized proteins, and oxidation can induce protein misfolding (Tarrago et al., 2012). Thus, MsrAB deficiency may trigger a secretion stress response likely to degrade the misfolded proteins, which could interfere with the correct functionality of the cell (Sarvas et al., 2004). In conclusion, msraB expression may prevent extracellular accumulation of faulty proteins to avoid negative effects in the exported/secreted proteins.

We have shown previously that Met residues in toxin-related proteins may act as ROS scavengers before being secreted (Madeira et al., 2015), and we report here that $\operatorname{Met}(\mathrm{O})$ in toxin-related proteins are MsrAB substrates. This indicates that Met residues in toxin-related proteins contribute to the endogenous antioxidant system (Levine et al., 1996, 1999; Luo and Levine, 2009; Kim, 2013), and thus to the cellular redox homeostasis of B. cereus (Duport et al., 2016). The reversible oxidation of Met to $\operatorname{Met}(\mathrm{O})$ has been suggested to be a mechanism for modulating protein activity (Kanayama et al., 2002). Therefore, catalyzed reduction of $\operatorname{Met}(\mathrm{O})$ in toxin-related proteins could be an antioxidant mechanism and a protein regulatory mechanism. This raises important questions about the role of this modification in the biological activity of toxins, and thus in the cytotoxicity of $B$. cereus according to growth phase.

\section{AUTHOR CONTRIBUTIONS}

JM and CD designed the whole experiments. BA and JA helped to design proteomic experiments. JM carried out experiments. $\mathrm{CD}$ wrote the manuscript and all authors approved the final manuscript.

\section{SUPPLEMENTARY MATERIAL}

The Supplementary Material for this article can be found online at: http://journal.frontiersin.org/article/10.3389/fmicb. 2017.01342/full\#supplementary-material 


\section{REFERENCES}

Abbas, C. A., and Sibirny, A. A. (2011). Genetic control of biosynthesis and transport of riboflavin and flavin nucleotides and construction of robust biotechnological producers. Microbiol. Mol. Biol. Rev. 75, 321-360. doi: 10.1128/MMBR.00030-10

Alamuri, P., and Maier, R. J. (2004). Methionine sulphoxide reductase is an important antioxidant enzyme in the gastric pathogen Helicobacter pylori. Mol. Microbiol. 53, 1397-1406. doi: 10.1111/j.1365-2958.2004.04190.x

Alamuri, P., and Maier, R. J. (2006). Methionine sulfoxide reductase in Helicobacter pylori: interaction with methionine-rich proteins and stressinduced expression. J. Bacteriol. 188, 5839-5850. doi: 10.1128/JB.00430-06

Alonzo, F. III, Xayarath, B., Whisstock, J. C., and Freitag, N. E. (2011). Functional analysis of the Listeria monocytogenes secretion chaperone PrsA2 and its multiple contributions to bacterial virulence. Mol. Microbiol. 80, 1530-1548. doi: 10.1111/j.1365-2958.2011.07665.x

Altincicek, B., Linder, M., Linder, D., Preissner, K. T., and Vilcinskas, A. (2007). Microbial metalloproteinases mediate sensing of invading pathogens and activate innate immune responses in the lepidopteran model host Galleria mellonella. Infect. Immun. 75, 175-183. doi: 10.1128/IAI.01385-06

Arantes, O., and Lereclus, D. (1991). Construction of cloning vectors for Bacillus thuringiensis. Gene 108, 115-119. doi: 10.1016/0378-1119(91)90495-W

Arnaud, M., Chastanet, A., and Debarbouille, M. (2004). New vector for efficient allelic replacement in naturally nontransformable, low-GCcontent, gram-positive bacteria. Appl. Environ. Microbiol. 70, 6887-6891. doi: 10.1128/AEM.70.11.6887-6891.2004

Banerjee, A., Adolph, R. S., Gopalakrishnapai, J., Kleinboelting, S., Emmerich, C., Steegborn, C., et al. (2015). A universal stress protein (USP) in mycobacteria binds cAMP. J. Biol. Chem. 290, 12731-12743. doi: 10.1074/jbc.M115.644856

Beloin, C., Valle, J., Latour-Lambert, P., Faure, P., Kzreminski, M., Balestrino, D., et al. (2004). Global impact of mature biofilm lifestyle on Escherichia coli K-12 gene expression. Mol. Microbiol. 51, 659-674. doi: 10.1046/j.1365-2958.2003.03865.x

Brynildsen, M. P., Winkler, J. A., Spina, C. S., Macdonald, I. C., and Collins, J. J. (2013). Potentiating antibacterial activity by predictably enhancing endogenous microbial ROS production. Nat. Biotechnol. 31, 160-165. doi: 10.1038/nbt.2458

Chubukov, V., and Sauer, U. (2014). Environmental dependence of stationaryphase metabolism in Bacillus subtilis and Escherichia coli. Appl. Environ. Microbiol. 80, 2901-2909. doi: 10.1128/AEM.00061-14

Clair, G., Lorphelin, A., Armengaud, J., and Duport, C. (2013). OhrRA functions as a redox-responsive system controlling toxinogenesis in Bacillus cereus. J. Proteomics 94, 527-539. doi: 10.1016/j.jprot.2013.10.024

Clair, G., Roussi, S., Armengaud, J., and Duport, C. (2010). Expanding the known repertoire of virulence factors produced by Bacillus cereus through early secretome profiling in three redox conditions. Mol. Cell. Proteomics 9, 1486-1498. doi: 10.1074/mcp.M000027-MCP201

Craney, A., Dix, M. M., Adhikary, R., Cravatt, B. F., and Romesberg, F. E. (2015). An alternative terminal step of the general secretory pathway in Staphylococcus aureus. MBio 6:e01178-15. doi: 10.1128/mBio.01178-15

Dedieu, A., Gaillard, J. C., Pourcher, T., Darrouzet, E., and Armengaud, J. (2011). Revisiting iodination sites in thyroglobulin with an organ-oriented shotgun strategy. J. Biol. Chem. 286, 259-269. doi: 10.1074/jbc.M110.159483

De Groot, A., Dulermo, R., Ortet, P., Blanchard, L., Guerin, P., Fernandez, B., et al. (2009). Alliance of proteomics and genomics to unravel the specificities of Sahara bacterium Deinococcus deserti. PLoS Genet. 5:e1000434. doi: 10.1371/journal.pgen.1000434

Drazic, A., and Winter, J. (2014). The physiological role of reversible methionine oxidation. Biochim. Biophys. Acta 1844, 1367-1382. doi: 10.1016/j.bbapap.2014.01.001

Dukan, S., and Nystrom, T. (1999). Oxidative stress defense and deterioration of growth-arrested Escherichia coli cells. J. Biol. Chem. 274, 26027-26032. doi: 10.1074/jbc.274.37.26027

Dupierris, V., Masselon, C., Court, M., Kieffer-Jaquinod, S., and Bruley, C. (2009). A toolbox for validation of mass spectrometry peptides identification and generation of database: IRMa. Bioinformatics 25, 1980-1981. doi: 10.1093/bioinformatics/btp301

Duport, C., Jobin, M., and Schmitt, P. (2016). Adaptation in Bacillus cereus: from stress to disease. Front. Microbiol. 7:1550. doi: 10.3389/fmicb.2016.01550
Duport, C., Zigha, A., Rosenfeld, E., and Schmitt, P. (2006). Control of enterotoxin gene expression in Bacillus cereus F4430/73 involves the redoxsensitive ResDE signal transduction system. J. Bacteriol. 188, 6640-6651. doi: 10.1128/JB.00702-06

Giomarelli, B., Visai, L., Hijazi, K., Rindi, S., Ponzio, M., Iannelli, F., et al. (2006). Binding of Streptococcus gordonii to extracellular matrix proteins. FEMS Microbiol. Lett. 265, 172-177. doi: 10.1111/j.1574-6968.2006. 00479.x

Hartmann, E. M., and Armengaud, J. (2014). N-terminomics and proteogenomics, getting off to a good start. Proteomics 14, 2637-2646. doi: $10.1002 /$ pmic.201400157

Hassouni, M. E., Chambost, J. P., Expert, D., Van Gijsegem, F., and Barras, F. (1999). The minimal gene set member msrA, encoding peptide methionine sulfoxide reductase, is a virulence determinant of the plant pathogen Erwinia chrysanthemi. Proc. Natl. Acad. Sci. U.S.A. 96, 887-892. doi: $10.1073 /$ pnas. 96.3 .887

Imlay, J. A. (2013). The molecular mechanisms and physiological consequences of oxidative stress: lessons from a model bacterium. Nat. Rev. Microbiol. 11, 443-454. doi: 10.1038/nrmicro3032

Kabashima, Y., Sone, N., Kusumoto, T., and Sakamoto, J. (2013). Purification and characterization of malate:quinone oxidoreductase from thermophilic Bacillus sp. PS3. J. Bioenerg. Biomembr. 45, 131-136. doi: 10.1007/s10863-012-9485-5

Kanayama, A., Inoue, J., Sugita-Konishi, Y., Shimizu, M., and Miyamoto, Y. (2002). Oxidation of Ikappa B alpha at methionine 45 is one cause of taurine chloramine-induced inhibition of NF-kappa B activation. J. Biol. Chem. 277, 24049-24056. doi: 10.1074/jbc.M110832200

Kim, G., Weiss, S. J., and Levine, R. L. (2014). Methionine oxidation and reduction in proteins. Biochim. Biophys. Acta 1840, 901-905. doi: 10.1016/j.bbagen.2013.04.038

Kim, H. Y. (2013). The methionine sulfoxide reduction system: selenium utilization and methionine sulfoxide reductase enzymes and their functions. Antioxid. Redox Signal. 19, 958-969. doi: 10.1089/ars.2012.5081

Koc, A., Gasch, A. P., Rutherford, J. C., Kim, H. Y., and Gladyshev, V. N. (2004). Methionine sulfoxide reductase regulation of yeast lifespan reveals reactive oxygen species-dependent and -independent components of aging. Proc. Natl. Acad. Sci. U.S.A. 101, 7999-8004. doi: 10.1073/pnas.0307929101

Laouami, S., Clair, G., Armengaud, J., and Duport, C. (2014). Proteomic evidences for rex regulation of metabolism in toxin-producing Bacillus cereus ATCC 14579. PLoS ONE 9:e107354. doi: 10.1371/journal.pone.0107354

Laouami, S., Messaoudi, K., Alberto, F., Clavel, T., and Duport, C. (2011). Lactate dehydrogenase A promotes communication between carbohydrate catabolism and virulence in Bacillus cereus. J. Bacteriol. 193, 1757-1766. doi: 10.1128/JB.00024-11

Levine, R. L., Berlett, B. S., Moskovitz, J., Mosoni, L., and Stadtman, E. R. (1999). Methionine residues may protect proteins from critical oxidative damage. Mech. Ageing Dev. 107, 323-332. doi: 10.1016/S0047-6374(98) 00152-3

Levine, R. L., Mosoni, L., Berlett, B. S., and Stadtman, E. R. (1996). Methionine residues as endogenous antioxidants in proteins. Proc. Natl. Acad. Sci. U.S.A. 93, 15036-15040. doi: 10.1073/pnas.93.26.15036

Luo, S., and Levine, R. L. (2009). Methionine in proteins defends against oxidative stress. FASEB J. 23, 464-472. doi: 10.1096/fj.08-118414

Madeira, J. P., Alpha-Bazin, B., Armengaud, J., and Duport, C. (2015). Time dynamics of the Bacillus cereus exoproteome are shaped by cellular oxidation. Front. Microbiol. 6:342. doi: 10.3389/fmicb.2015.00342

Madeira, J. P., Alpha-Bazin, B., Armengaud, J., Omer, H., and Duport, C. (2016a). Proteome data to explore the impact of pBClin15 on Bacillus cereus ATCC 14579. Data Brief 8, 1243-1246. doi: 10.1016/j.dib.2016.07.042

Madeira, J. P., Omer, H., Alpha-Bazin, B., Armengaud, J., and Duport, C. (2016b). Deciphering the interactions between the Bacillus cereus linear plasmid, $\mathrm{pBClin} 15$, and its host by high-throughput comparative proteomics. J. Proteomics 146, 25-33. doi: 10.1016/j.jprot.2016.06.022

Marteyn, B., West, N. P., Browning, D. F., Cole, J. A., Shaw, J. G., Palm, F., et al. (2010). Modulation of Shigella virulence in response to available oxygen in vivo. Nature 465, 355-358. doi: 10.1038/nature08970

Martin, E., Rosenthal, R. E., and Fiskum, G. (2005). Pyruvate dehydrogenase complex: metabolic link to ischemic brain injury and target of oxidative stress. J. Neurosci. Res. 79, 240-247. doi: 10.1002/jnr.20293 
Moriarty-Craige, S. E., and Jones, D. P. (2004). Extracellular thiols and thiol/disulfide redox in metabolism. Annu. Rev. Nutr. 24, 481-509. doi: 10.1146/annurev.nutr.24.012003.132208

Moskovitz, J., Rahman, M. A., Strassman, J., Yancey, S. O., Kushner, S. R., Brot, N., et al. (1995). Escherichia coli peptide methionine sulfoxide reductase gene: regulation of expression and role in protecting against oxidative damage. J. Bacteriol. 177, 502-507. doi: 10.1128/jb.177.3.502-507.1995

Murphy, E. (1985). Nucleotide sequence of a spectinomycin adenyltransferase $\mathrm{AAD}(9)$ determinant from Staphylococcus aureus and its relationship to AAD(3") (9). Mol. Gen. Genet. 200, 33-39. doi: 10.1007/BF00383309

Omer, H., Alpha-Bazin, B., Brunet, J. L., Armengaud, J., and Duport, C. (2015). Proteomics identifies Bacillus cereus EntD as a pivotal protein for the production of numerous virulence factors. Front. Microbiol. 6:1004. doi: $10.3389 /$ fmicb. 2015.01004

Ralser, M., Wamelink, M. M., Kowald, A., Gerisch, B., Heeren, G., Struys, E. A., et al. (2007). Dynamic rerouting of the carbohydrate flux is key to counteracting oxidative stress. J. Biol. 6:10. doi: 10.1186/jbiol61

Richardson, A. R., Somerville, G. A., and Sonenshein, A. L. (2015). Regulating the intersection of metabolism and pathogenesis in Gram-positive bacteria. Microbiol. Spectr. 3:MBP-0004-2014. doi: 10.1128/microbiolspec.MBP0004-2014

Ritchie, M. E., Phipson, B., Wu, D., Hu, Y., Law, C. W., Shi, W., et al. (2015). limma powers differential expression analyses for RNA-sequencing and microarray studies. Nucleic Acids Res. 43:e47. doi: 10.1093/nar/gkv007

Robinson, M. D., Mccarthy, D. J., and Smyth, G. K. (2010). edgeR: a bioconductor package for differential expression analysis of digital gene expression data. Bioinformatics 26, 139-140. doi: 10.1093/bioinformatics/btp616

Rosenfeld, E., Duport, C., Zigha, A., and Schmitt, P. (2005). Characterization of aerobic and anaerobic vegetative growth of the food-borne pathogen Bacillus cereus F4430/73 strain. Can. J. Microbiol. 51, 149-158. doi: 10.1139/w04-132

Ross, D., Kepa, J. K., Winski, S. L., Beall, H. D., Anwar, A., and Siegel, D. (2000). $\mathrm{NAD}(\mathrm{P}) \mathrm{H}$ :quinone oxidoreductase 1 (NQO1): chemoprotection, bioactivation, gene regulation and genetic polymorphisms. Chem. Biol. Interact. 129, 77-97. doi: 10.1016/S0009-2797(00)00199-X

Ryan, A., Kaplan, E., Nebel, J. C., Polycarpou, E., Crescente, V., Lowe, E., et al. (2014). Identification of $\mathrm{NAD}(\mathrm{P}) \mathrm{H}$ quinone oxidoreductase activity in azoreductases from $P$. aeruginosa: azoreductases and $\mathrm{NAD}(\mathrm{P}) \mathrm{H}$ quinone oxidoreductases belong to the same FMN-dependent superfamily of enzymes. PLoS ONE 9:e98551. doi: 10.1371/journal.pone.0098551

Sarvas, M., Harwood, C. R., Bron, S., and Van Dijl, J. M. (2004). Posttranslocational folding of secretory proteins in Gram-positive bacteria. Biochim. Biophys. Acta 1694, 311-327. doi: 10.1016/j.bbamcr.2004.04.009

Singh, K., and Singh, V. K. (2012). Expression of four methionine sulfoxide reductases in Staphylococcus aureus. Int. J. Microbiol. 2012:719594. doi: 10.1155/2012/719594

Stadtman, E. R., Van Remmen, H., Richardson, A., Wehr, N. B., and Levine, R. L. (2005). Methionine oxidation and aging. Biochim. Biophys. Acta 1703, 135-140. doi: 10.1016/j.bbapap.2004.08.010
Stenfors Arnesen, L. P., Fagerlund, A., and Granum, P. E. (2008). From soil to gut: Bacillus cereus and its food poisoning toxins. FEMS Microbiol. Rev. 32, 579-606. doi: 10.1111/j.1574-6976.2008.00112.x

Tarrago, L., Kaya, A., Weerapana, E., Marino, S. M., and Gladyshev, V. N. (2012) Methionine sulfoxide reductases preferentially reduce unfolded oxidized proteins and protect cells from oxidative protein unfolding. J. Biol. Chem. 287, 24448-24459. doi: 10.1074/jbc.M112.374520

Vattanaviboon, P., Seeanukun, C., Whangsuk, W., Utamapongchai, S., and Mongkolsuk, S. (2005). Important role for methionine sulfoxide reductase in the oxidative stress response of Xanthomonas campestris pv. phaseoli. J. Bacteriol. 187, 5831-5836. doi: 10.1128/JB.187.16.5831-5836.2005

Vitikainen, M., Lappalainen, I., Seppala, R., Antelmann, H., Boer, H., Taira, S., et al. (2004). Structure-function analysis of PrsA reveals roles for the parvulin-like and flanking $\mathrm{N}$ - and C-terminal domains in protein folding and secretion in Bacillus subtilis. J. Biol. Chem. 279, 19302-19314. doi: 10.1074/jbc.M400861200

Vitreschak, A. G., Rodionov, D. A., Mironov, A. A., and Gelfand, M. S. (2002) Regulation of riboflavin biosynthesis and transport genes in bacteria by transcriptional and translational attenuation. Nucleic Acids Res. 30, 3141-3151. doi: $10.1093 /$ nar/gkf433

Vogt, W. (1995). Oxidation of methionyl residues in proteins - tools, targets, and reversal. Free Radic. Biol. Med. 18, 93-105. doi: 10.1016/0891-5849(94)00158-G

Weissbach, H., Etienne, F., Hoshi, T., Heinemann, S. H., Lowther, W. T., Matthews, B., et al. (2002). Peptide methionine sulfoxide reductase: structure, mechanism of action, and biological function. Arch. Biochem. Biophys. 397, 172-178. doi: 10.1006/abbi.2001.2664

Westers, H., Westers, L., Darmon, E., Van Dijl, J. M., Quax, W. J., and Zanen, G. (2006). The CssRS two-component regulatory system controls a general secretion stress response in Bacillus subtilis. FEBS J. 273, 3816-3827. doi: 10.1111/j.1742-4658.2006.05389.x

Wizemann, T. M., Moskovitz, J., Pearce, B. J., Cundell, D., Arvidson, C. G., So, M., et al. (1996). Peptide methionine sulfoxide reductase contributes to the maintenance of adhesins in three major pathogens. Proc. Natl. Acad. Sci. U.S.A. 93, 7985-7990. doi: 10.1073/pnas.93.15.7985

Zwietering, M., Jongenburger, I., Rombouts, F., and Van't Riet, K. (1990). Modeling of the bacterial growth curve. Appl. Environ. Microbiol. 56, 1875-1881.

Conflict of Interest Statement: The authors declare that the research was conducted in the absence of any commercial or financial relationships that could be construed as a potential conflict of interest.

Copyright (c) 2017 Madeira, Alpha-Bazin, Armengaud and Duport. This is an openaccess article distributed under the terms of the Creative Commons Attribution License (CC BY). The use, distribution or reproduction in other forums is permitted, provided the original author(s) or licensor are credited and that the original publication in this journal is cited, in accordance with accepted academic practice. No use, distribution or reproduction is permitted which does not comply with these terms. 